\title{
Open disclosure: ethical, professional and legal obligations, and the way forward for regulation
}

Angus J F Finlay Medical Student

Cameron L Stewart

BEc, LLB(Hons), PhD, Professor and Director ${ }^{2}$

Malcolm Parker MB BS, MLitt, MD Professor of Medical Ethics

1 School of Medicine University of Queensland Brisbane, QLD.

2 Centre for Health Governance, Law and Ethics, Sydney Law School, University of Sydney, Sydney, NSW.

angus.finlay@ uqconnect.edu.au

doi: 10.5694/mjal2.10734

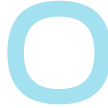

pen disclosure (OD) is the process of "open discussion of incidents that result in harm to a patient while receiving health care" ${ }^{1}$ OD requires doctors to inform patients that an adverse event has occurred. As additional information surrounding the event is gathered, the patient is notified of the probable long-term outcomes and informed of how the system is being modified to prevent recurrence. ${ }^{2,3}$ Thus, the formal process of OD involves the following elements: ${ }^{1}$

- notification to a patient and/or his or her legal representative about what has occurred;

- apology or expression of regret;

- factual explanation of what happened;

- indication of potential long-term outcomes for the patient; and

- systemic changes being made to prevent recurrence.

OD should be implemented immediately after the recognition of an adverse event, long before detailed investigations of what happened may be carried out. ${ }^{1}$ During a national meeting in 2008, Australian health ministers resolved to implement $\mathrm{OD}$ in health care settings throughout Australia. Despite the existence of a national guideline, the national Open disclosure standard (henceforth "national standard"), ${ }^{1}$ doctors have been slow to embrace OD. ${ }^{2}$ This may be because of uncertainty about doctors' legal and

\section{Sumnary}

- Open disclosure (OD) after adverse health care events is the subject of a national standard that has been implemented in state health policy documents, and is included in the Medical Board of Australia's code of conduct for doctors.

- Nevertheless, doctors have been slow to embrace the practice of OD.

- There is a strong ethical case for implementing OD in the primary interests of patients, and additionally from a medicolegal risk management point of view.

- There are no statutory requirements in relation to OD, but common law judgments have imposed a duty of OD in tort and contract.

- There are a number of barriers to the better uptake and implementation of OD, including perceptions of legal risk, lack of education and training, reluctance to admit error, uncertainty concerning what and how much to disclose, and the variations in state and territory "apology laws".

- The implementation of OD could be improved by making apology laws consistent across jurisdictions, including providing "blanket" cover for admissions of fault; by preventing insurers voiding contracts when apologies are made, either through self-regulation or legislation; and by inserting OD obligations into different structures within the health system.

\section{Health department policies on open disclosure, by state and territory}

\begin{tabular}{ll}
$\begin{array}{l}\text { State or } \\
\text { territory }\end{array}$ & Title of open disclosure policy document or website \\
\hline ACT & Open disclosure policy \\
NSW & $\begin{array}{l}\text { Open disclosure } \\
\text { NT }\end{array}$ \\
& $\begin{array}{l}\text { Report to the Department of Health and Families NT on } \\
\text { governance of complaint handling and implementation of open } \\
\text { disclosure at Royal Darwin Hospital }\end{array}$ \\
Qld & $\begin{array}{l}\text { Open Disclosure Program (website) } \\
\text { SA }\end{array}$ \\
& $\begin{array}{l}\text { Open Disclosure (website) } \\
\text { Tas }\end{array}$ \\
Vic & $\begin{array}{l}\text { Department of Health and Human Services open disclosure } \\
\text { policy }\end{array}$ \\
WA & $\begin{array}{l}\text { Clinical risk management: open disclosure (website) } \\
\text { requirements for health professionals working in Western }\end{array}$ \\
& Australia
\end{tabular}

Link

http://www.health.act.gov.au/c/health?a=dlpubpoldoc\&document= 1930

http://www.health.nsw.gov.au/policies/pd/2007/PD2007_040.html http://digitallibrary.health.nt.gov.au/dspace/bitstream/10137/255/1/ Ray\%20Norman\%20Complaints\%20Management\%20Review.pdf http://www.health.qld.gov.au/psq/od/webpages/od_homepage.asp http://www.sahealth.sa.gov.au/wps/wcm/connect/Public+Content/ $\mathrm{SA}+$ Health+Internet/Clinical+resources/Safety+and+quality/ Governance+for+Safety+and+Quality+in+health+service+ organisations/Open+disclosure

http://www.health.vic.gov.au/clinrisk/opendisc.htm http://www.safetyandquality.health.wa.gov.au/involving_patient/ open_disclosure.cfm

ACT = Australian Capital Territory. NSW = New South Wales. NT = Northern Territory. Qld $=$ Queensland. SA $=$ South Australia. Tas $=$ Tasmania. Vic $=$ Victoria WA $=$ Western Australia.

*A draft is currently being considered but is not available on the Department of Health and Human Services website. 


\section{Key steps in the open disclosure (OD) process}

Doctors should be aware of the key steps in the OD process, as provided in s3.10 of Good medical practice: a code of conduct for doctors in Australia: ${ }^{6}$

- recognising what has happened;

- acting immediately to rectify the problem, if possible, including seeking any necessary help and advice;

- explaining to the patient as promptly and fully as possible what has happened and the anticipated short-term and long-term consequences;

- acknowledging any patient distress and providing appropriate support;

- complying with any relevant policies, procedures and reporting requirements, subject to advice from your medical indemnity insurer;

- reviewing adverse events and implementing changes to reduce the risk of recurrence;

- reporting adverse events to the relevant authority, as necessary; and

- ensuring patients have access to information about the processes for making a complaint (for example, through the relevant health care complaints commission or medical board).

professional obligations in relation to OD, and concern about medicolegal risk. ${ }^{2}$ In this article, we clarify the relevant legal and ethical obligations imposed on doctors, and make suggestions for specific reforms to improve the adoption of OD. We argue that OD after an adverse event should now be treated as ethically mandated, and that the law should impose clear statutory obligations and protections for OD that mirror the common law developments. Finally, we discuss some of the barriers to OD, with suggestions for how they can be overcome.

\section{The professional underpinnings of OD}

There is a strong ethical case for OD, which many see as a moral imperative. ${ }^{3-5}$ After extensive national consultation in 2002, the national standard was prepared. It is arguably the most important document on OD at the policy level in Australia. Each state and territory has incorporated the national standard into its own health and quality policies to varying degrees (Box 1). It has also been incorporated into the Medical Board of Australia's publication Good medical practice: a code of conduct for doctors in Australia, ${ }^{6}$ and the guidelines of the code are recognised by each state's Health Practitioner Regulation National Law Act as evidence of what constitutes appropriate professional conduct for doctors practising in Australia. Concerning the disclosure process, Good medical practice states:

When adverse events occur, you have a responsibility to be open and honest in your communication with your patient, to review what has occurred and to report appropriately.

Eight subclauses follow, which describe the steps to be taken in the OD process (Box 2). Further, OD is generally strongly supported by state bodies such as the New South Wales Clinical Excellence Commission, which explicitly includes OD as part of the feedback process after adverse events, ${ }^{7}$ and by complaints organisations, such as Queens-

\section{Necessary reforms in open disclosure (OD)}

The following reforms should be adopted for OD to be successful:

- uniform laws that provide a blanket exclusion of apologies from being used in evidence;

- insurers must be prevented from voiding indemnity contracts when apologies are made in compliance with the national Open disclosure standard; ${ }^{1}$ and

- establishment of national provider responsibilities to implement OD.

land's Health Quality and Complaints Commission (HQCC). ${ }^{8}$ HQCC data show that complainants' most frequently desired outcome is an explanation or apology, and suggest that OD is not consistently performed well. ${ }^{8}$

\section{Legal obligations for open disclosure}

There is presently no statutory obligation for OD to patients after an adverse event. However, there is a line of common law authority which supports OD as either part of the duty of care or as an implied term in the contract for medical services. ${ }^{3,4,9}$

This duty resulting from common law was affirmed in Wighton $v$ Arnot, ${ }^{10}$ where the treating surgeon suspected that his patient sustained a nerve injury during surgery. The court found that early disclosure, investigation and treatment would have greatly improved the patient's prognosis. Further, timely disclosure may have facilitated repair of the damaged nerve, avoiding a suit in negligence. Studdert J stated, "The plaintiff had a right to know, and the defendant had a duty to inform her, that he had severed a nerve" ${ }^{10}$

In addition to tort law, OD may be considered part of the implied contractual obligation to provide reasonable care to both public and private patients. In an English case, Naylor v Preston Area Health Authority, Donaldson, MR, stated that OD is a necessary component of the general duty of care that doctors and hospital authorities hold towards patients, and is founded in both contract and tort law. $^{11}$

\section{The problem of avoidance and the apology paradox}

Despite compelling professional obligations and common law developments, Australian doctors have generally avoided OD. ${ }^{2}$ Australian and United States studies of doctors have identified that the main barriers to routine $\mathrm{OD}$ are fear of an increase in medicolegal risk and a lack of training in the OD process. ${ }^{2,12-14}$

Other significant barriers cited include embarrassment at acknowledging an error, and uncertainty as to how much information should be disclosed. Prominent Australian commentators have summarised the disparity between the ethical obligations for OD and its poor uptake in practice:

In a perfect world, medical ethics should be sufficient to drive health professionals' commitment to $\mathrm{OD}$, but the 
reality is that comfort on the medicolegal front is likely to prove a useful carrot. ${ }^{15}$

The conflict between wishing to acknowledge error (out of moral obligation to the patient, as well as the probability that this will reduce the risk of litigation) but at the same time not wishing to admit liability (because it may increase the chance of litigation) is a core tension in OD practice. Interestingly, small trials of OD in the US have shown reductions in litigation, ${ }^{16,17}$ but it should be noted that the empirical evidence on the effect of OD on litigation rates is not yet conclusive. ${ }^{18,19}$

The apology paradox has meant that legal reform has focused on the so-called apology laws. These laws were introduced in Australia during the early 21st century after the Review of the law of negligence report. ${ }^{20}$ They aim to prevent apology statements from being used as admissions of liability. Unfortunately their form has varied across states and territories, leading to confusion about what kinds of statement they protect. ${ }^{2,8,15}$ For example, in Queensland and NSW, these laws refer to both expressions of regret (that do not admit or imply fault) and apologies (expressions of sympathy to a patient that may admit or imply fault). ${ }^{21,22}$ In Tasmania, by contrast, the laws stop short of making apologies that include the admission of fault inadmissible in court. ${ }^{23}$ Moreover, even if the apologies themselves are not admissible in court, discussion of the events leading up to the error is still likely to be so. ${ }^{15}$ Consequently, the national standard currently warns against explicit admissions of liability and speaks instead of "expressions of regret". The resulting uncertainties may lead to carefully worded, insincere apologies that assume no responsibility for the adverse event for fear of litigation, and, again, paradoxically increase the likelihood of disgruntled patients bringing about actions against doctors. ${ }^{24}$

Studdert and Richardson have argued that Australian legal regimes must offer more reassurance to doctors who practise OD. With greater statutory protection, further training and experience in OD can then proceed. ${ }^{15}$

The recent review of the national standard by the Australian Commission on Safety and Quality in Health Care recommended that the national standard be amended to:

describe the basic principles and components of an apology or expression of regret (including the words $I$ am or we are sorry) in the context of patient harm, but not be too prescriptive, due to

- the complexity and uniqueness of individual incidents and consequent disclosure process

- variations in legislative context between jurisdictions. ${ }^{25}$

This again illustrates the problem of the current apology laws and the variation across jurisdictions - how can doctors sincerely say they are sorry unless they explain why?

\section{The way forward}

For OD to be successful, three basic reforms should be adopted (Box 3). First, we agree with Studdert and Richardson that laws should be "broadly consistent across jurisdictions". ${ }^{15}$ Further, we urge national uniformity of the laws incorporating blanket cover for all apologies and statements of regret including admissions of fault. Moreover, all these statements should be legally inadmissible for all purposes, to remove any fear that they may be used as evidence. Informed opinion suggests that it is unlikely, even in the current legal context, that Australian courts would give weight to statements indicating or implying fault in states where apologies remain unprotected. ${ }^{26}$ In the non-medical case of Dovuro $v$ Wilkins, ${ }^{27}$ Gummow J explained that admissions of negligence are of little value in helping the court come to its conclusions about whether negligence has actually occurred. Nevertheless, without statutory reform, doubt will remain, and this will encourage doctors to remain hesitant about including sincere apologies in OD.

Second, the inadmissibility of apology evidence is of significant benefit to insurers. Consequently, we argue that insurers should be prevented from avoiding their responsibilities when apologies are made. The insurance industry could regulate itself in order to prevent industry members from voiding contracts when statements are made in accordance with the national standard. Alternatively, the federal government could use its powers to regulate the insurance industry to legislate such a change. In the interests of fairness, such a law should include a sunset clause so that after a predetermined period, its impact on apologies and insurance can be assessed. Of course, this will also require negotiation on the part of regulators as to how to define and measure OD practices in accordance with the national standard.

Finally, OD needs to be implanted directly into the bureaucratic structures of the new federal health system. Lessons can be learned from the current United Kingdom inquiry into the National Health Service (NHS) contractual standards for OD. ${ }^{28,29}$ The government has been unhappy with the uptake of OD under the current NHS constitution, and has recently decided to pursue a contractual duty to ensure compliance. ${ }^{30}$ From April 2013, the requirement to undertake OD will be formally included in contracts offered to NHS health care providers, with relevant breaches of contract possibly resulting in reduced funding, mandatory review, and remedial action. ${ }^{28}$

Similar obligations could be inserted with relative ease into Australia's new Health Networks and Medicare Locals system, and be audited by the National Health Performance Authority under the National Health Reform Act 2011. At state and territory levels, regulations could require hospital and health boards to incorporate OD practice. For example, the Hospital and Health Boards Regulation 2012 (Q1d) already requires Queensland hospital services to create clinical engagement strategies which "have regard to national and State strategies, policies, agreements and standards relevant to promoting consultation with health professionals working in the Service" ${ }^{31}$ It would be a small step from there to expressly include the national standard as part of clinical strategies. Such regulatory techniques would strengthen the existing OD policies and further encourage the use of the national standard. The recent review of the national standard proposes many other potential methods to increase OD rates, including explicit policy at the local level (in addition to state policies), and undergraduate and postgraduate training. ${ }^{25}$ 


\section{Conclusions}

We have argued that OD is ethically and legally mandated. We have also shown that significant barriers remain that are impeding its adoption, and we have recommended three basic reforms, which can be tested over time for their effectiveness. Finally, we should remind ourselves that the reason for adopting OD is not to reduce litigation, although this may be a desirable side effect. Rather, the point is to encourage health systems that value honesty and transparency so that errors can be reduced and injured patients can be properly cared for.

Competing interests: No relevant disclosures.

Provenance: Not commissioned; externally peer reviewed.

1 Australian Commission on Safety and Quality in Health Care. Open disclosure standard: a national standard for open communication in public and private hospitals, following an adverse event in health care. Canberra: Commonwealth of Australia, 2003. http://www.health.qld.gov.au/psq/od/docs/odst.pdf (accessed Apr 2013).

2 Studdert DM, Piper D, ledema R. Legal aspects of open disclosure II: attitudes of health professionals - findings from a national survey. Med J Aust 2010; 193: 351-355.

3 Madden B, Cockburn T. Duty to disclose medical error in Australia. Aust Health Law Bull 2005; 14: 13-20.

4 Madden B, Cockburn T. Bundaberg and beyond: duty to disclose adverse events to patients. J Law Med 2007; 14: 501-527.

5 ledema RA, Mallock NA, Sorensen RJ, et al. The National Open Disclosure Pilot: evaluation of a policy implementation initiative. Med J Aust 2008; 188: 397400.

6 Medical Board of Australia. Good medical practice: a code of conduct for doctors in Australia. Melbourne: Australian Medical Council Limited, 2010. http://www.amc.org.au/index.php/about/good-medical-practice (accessed Mar 2013).

7 Clinical Excellence Commission and NSW Department of Health. Clinical incident management in the NSW public health system: looking, learning, acting. 2011. http://www.cec.health.nsw.gov.au/_documents/publications/ hssll-1012_cec-cimreport_j2j-2010_web.pdf (accessed Mar 2013).

8 Health Quality and Complaints Commission. Submission to Australian Commission on Safety and Quality in Health Care: review of the ACSQHC open disclosure standard. 2012. http://www.hqcc.qld.gov.au/Resources/ Documents/Submission-ACSQHC-open-disclosure-standard.pdf (accessed Dec 2012).

9 Stewart C, Kerridge I, Parker M. The Australian medico-legal handbook. Sydney: Churchill Livingstone Elsevier, 2008: 46-49.

10 Wighton v Arnot [2005] NSWSC 637.

11 Naylor v Preston Area Health Authority [1987] 2 All ER 353.
12 Solomon RC. Ethical issues in medical malpractice. Emerg Med Clin North Am 2006; 24: 733-747.

13 Gallagher TH, Waterman AD, Ebers AG, et al. Patients' and physicians' attitudes regarding the disclosure of medical errors. JAMA 2003; 289: 1001-1007.

14 Lamb RM, Studdert DM, Bohmer RM, et al. Hospital disclosure practices: results of a national survey. Health Aff (Millwood) 2003; 22: 73-83.

15 Studdert DM, Richardson MW. Legal aspects of open disclosure: a review of Australian law. Med J Aust 2010; 193: 273-276.

16 Quinn RE, Eichler MC. The 3Rs program: the Colorado experience. Clin Obstet Gynecol 2008; 51: 709-718.

17 Kachalia A, Kaufman SR, Boothman R, et al. Liability claims and costs before and after implementation of a medical error disclosure program. Ann Intern Med 2010; 153: 213-221.

18 Gallagher TH, Studdert D, Levinson W. Disclosing harmful medical errors to patients. NEngl J Med 2007; 356: 2713-2719.

19 ledema R, Sorensen R, Piper D. Open disclosure: a review of the literature. Sydney: Australian Commission on Safety and Quality in Health Care and University of Technology, Sydney, 2008.

20 Australian Government Treasury Law of Negligence Review Panel. Review of the law of negligence: final report. Canberra: Commonwealth of Australia, 2002. http://revofneg.treasury.gov.au/content/review2.asp (accessed Ma 2013).

21 Civil Liability Act 2003 (Qld), s. 72.

22 Civil Liability Act 2002 (NSW), s. 68-69.

23 Civil Liability Act 2003 (Tas), s. 7.

24 Vines P. Apologising to avoid liability: cynical civility or practical morality. Sydney L Rev 2005; 27: 483-505. http://sydney.edu.au/law/str/previous.shtml (accessed Mar 2013).

25 Australian Commission on Safety and Quality in Health Care. Open disclosure standard. Review report. Sydney: ACSOHC, 2012. http:// www.safetyandquality.gov.au/wp-content/uploads/2012/05/63652-OpenDisclosure-Standard-Review-Report-Final-Jun-2012.pdf (accessed Dec 2012).

26 Brown D. Open disclosure: morally right but is it legally safe? Presented at Medico-Legal Society of NSW Scientific Meeting, March 2008. http:// www.medicolegal.org.au/resources/publications-archive/p2008/opendisclosure-morally-right-but-is-it-legally-safe/brown/ (accessed Feb 2012).

27 Dovuro Pty Ltd v Wilkins [2003] HCA 51; 215 CLR 317; 201 ALR 139.

28 UK Department of Health Patient Safety Team. implementing a "duty of candour" a new contractual requirement on providers. Proposals for consultation. 2011. http://www.dh.gov.uk/en/Consultations/ Liveconsultations/DH_130400 (accessed Jan 2012).

29 UK Department of Health Patient Safety Team. implementing a "duty of candour" a new contractual requirement on providers. Analysis of consultation responses. 2012. https://www.wp.dh.gov.uk/publications/files/2012/11/ summary-of-consultation-responses-duty-of-candour.pdf (accessed Mar 2013).

30 Limb M. Peers' rejection of statutory duty of candour is a missed opportunity, say campaigners. BMJ 2012; 344: el116.

31 Hospital and Health Boards Regulation 2012 (Qld), s. 12. 